\title{
Optimizing antiemetic treatment for chemotherapy-induced nausea and vomiting in Japan: Update summary of the 2015 Japan Society of Clinical Oncology Clinical Practice Guidelines for Antiemesis
}

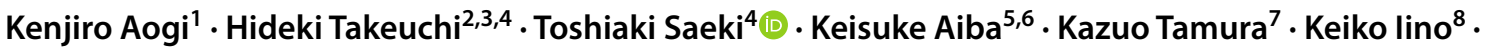 \\ Chiyo K. Imamura9,10 Kenji Okita $^{11,12} \cdot$ Yoshikazu Kagami $^{13} \cdot$ Ryuhei Tanaka $^{14} \cdot$ Kazuhiko Nakagawa $^{15}$. \\ Hirofumi Fujii ${ }^{16}$. Narikazu Boku ${ }^{17}$. Makoto Wada ${ }^{18}$. Tatsuo Akechi ${ }^{19}$. Hirotoshi lihara ${ }^{20}$. Shoichiro Ohtani ${ }^{21}$. \\ Ayako Okuyama ${ }^{22} \cdot K_{\text {Keiko Ozawa }}{ }^{23} \cdot$ Yong-II Kim ${ }^{24,25} \cdot$ Hidenori Sasaki $^{26} \cdot$ Yasuo Shima $^{27} \cdot$ Masayuki Takeda $^{15}$. \\ Eijiro Nagasaki $^{5,6} \cdot$ Toshihiko Nishidate $^{11,12} \cdot$ Takahiro Higashi $^{22} \cdot$ Kouichi Hirata $^{11,12}$
}

Received: 6 August 2020 / Accepted: 16 October 2020 / Published online: 8 November 2020

(c) The Author(s) 2020

\begin{abstract}
Patients with cancer should appropriately receive antiemetic therapies against chemotherapy-induced nausea and vomiting (CINV). Antiemetic guidelines play an important role in managing CINV. Accordingly, the first Japanese antiemetic guideline published in 2010 by the Japan Society of Clinical Oncology (JSCO) has considerably aided Japanese medical staff in providing antiemetic therapies across chemotherapy clinics. With the yearly advancements in antiemetic therapies, the Japanese antiemetic guidelines require revisions according to published evidence regarding antiemetic management worldwide. A revised version of the first antiemetic guideline that considered several upcoming evidences had been published online in 2014 (version 1.2), in which several updated descriptions were included. The 2015 JSCO clinical practice guideline for antiemesis (version 2.0) (in Japanese) has addressed clinical antiemetic concerns and includes four major revisions regarding (1) changes in emetogenic risk categorization for anti-cancer agents, (2) olanzapine usage as an antiemetic drug, (3) the steroid-sparing method, and (4) adverse drug reactions of antiemetic agents. We herein present an English update summary for the 2015 JSCO clinical practice guideline for antiemesis (version 2.0).
\end{abstract}

Keywords Antiemesis · Chemotherapy-induced nausea and vomiting $\cdot$ Clinical practice guideline

\section{Introduction}

Antiemetic therapies against chemotherapy-induced nausea and vomiting (CINV) should be developed and incorporated into cancer care protocols, while a framework for highquality management should be widely distributed to cancer care providers [1-3]. Several international clinical guidelines that disseminate proper antiemetic treatment based on newly published evidences have been available [4-6]. For practical guidance in chemotherapy, the first Japanese Society of Clinical Oncology (JSCO) clinical practice guideline for antiemesis had been published in 2010 with its English version being published in 2016 [7]. Approximately 51.0\%

Toshiaki Saeki

tsaeki@saitama-med.ac.jp

Extended author information available on the last page of the article of medical staff throughout Japanese chemotherapy clinics perform antiemetic therapies according to this guideline, while $42.6 \%$ use this as a reference [8]. Thus, this guideline has considerably helped antiemesis treatment across Japanese clinics.

Some international antiemetic guidelines, such as those by the American Society of Clinical Oncology (ASCO), National Comprehensive Cancer Network (NCCN), and Multinational Association of Supportive Care in Cancer (MASCC), had been revised according to recently available evidence [4-6]. Consistent with this, the first JSCO antiemetic guideline had been revised and published online in 2014 as version 1.2, with further revisions thereto resulting in the publication of the JSCO clinical practice guideline for antiemesis version 2.0 in 2015 [9]. 


\section{Methods \& Results}

Accordingly, the updated 2015 JSCO guideline contains four major revisions regarding (1) changes in emetogenic risk categorization for anticancer agents, (2) olanzapine usage as an antiemetic drug, (3) the steroid-sparing method, and (4) adverse drug reactions of antiemetic agents. Apart from the aforementioned revisions, the 2015 JSCO guideline discussed and provided updates on clinical antiemetic concerns. In addition, an online version of the said guideline (version 2.2) had been made available in 2018.

We herein present an English update summary of the 2015 JSCO clinical practice guideline for antiemesis (version 2.0).

\section{Materials and methods}

A working group of the JSCO developed the first and second version of the clinical practice guideline for antiemesis based on the Appraisal of Guidelines for Research and Evaluation (AGREE) II instrument (https://www.agreetrust .org/resource-centre/agree-ii/), a widely used standard for assessing the methodological quality of practice guidelines.

A draft of the guideline was developed based on systematically reviewed evidences for clinical questions (CQs). However, domestic factors, including ethnicity and health policy formation at the system level, required further consideration. Hence, a consensus was reached by all medical practitioners attending a consensus meeting, during which recommendations for antiemetic treatments were discussed considering Japanese medical circumstances.

\section{Literature search strategy}

The major international guidelines (i.e., NCCN, MASSC/ ESMO, and ASCO) had been utilized as sources of information [4-6], similar to the first version. A systematic review and meta-analysis of the effectiveness of antiemetic therapies were performed using MEDLINE searches and the Cochrane library [10]. Available meeting abstracts from the ASCO and MASSC annual meetings were also reviewed.

\section{Conflicts of interest for the guideline}

The update committee for the second version was assembled in accordance with ASCO's Conflict of Interest (COI) Management Procedures for Clinical Practice Guidelines (https:// www.asco.org/guidelinescoi). Subsequently, the COI committee reviewed the $\mathrm{COI}$ of each member.

\section{Recommendation grade used in the guideline}

Similar to the first version, recommendation grades were established as a guide for evidence evaluation:

A: Strongly recommended for clinical practice.

B: Recommend for clinical practice.

C1: Clinical practice may be useful despite the lack of high-level scientific evidence.

C2: Not recommended due to insufficient scientific evidence.

D: Clinical practice should be avoided.

\section{Emetogenic risks of intravenous and oral chemotherapeutic agents}

Tables 1 and 2 discuss the emetogenic risk categorization for anticancer agents provided in the outline portion of the second version. Emetogenic risks of intravenous and oral chemotherapeutic agents presented in the aforementioned tables are based on recommendations established with a high level of consensus in several guidelines, such as those by the NCCN, MASSC, and ASCO, and have been modified according to clinical data in published literatures considering the medical circumstances in Japan.

Emetogenic risk is evaluated according to the percentage of patients who experience acute emesis within $24 \mathrm{~h}$ of initiation/administration of the anticancer agent and is categorized in the same manner as that in the first version.

High emetogenic risk: $90 \%$ or more patients experience acute emesis.

Moderate emetogenic risk: $30-90 \%$ of patients experience acute emesis.

Low emetogenic risk: $10-30 \%$ of patients experience acute emesis.

Minimal emetogenic risk: fewer than $10 \%$ of patients experience acute emesis.

\section{Results}

\section{Summary of major updated issues}

The second version of Japanese antiemetic guideline included the following major updated issues from the first version (Tables 3, 4):

(1) Changes in emetogenic risk categorization for anticancer agents (Tables 1,2).

(2) Description regarding the usage of olanzapine (CQ2 and $\mathrm{CQ} 3$ ).

(3) Description regarding steroid sparing (CQ2 and CQ3). 
Table 1 Emetogenic risk category for intravenous chemotherapeutic agents

\begin{tabular}{|c|c|c|}
\hline JSCO emetogenic risk category & Agent (regimen) & \\
\hline High emetogenic risk (emetic frequency: $>90 \%$ ) & $\begin{array}{l}\text { Cisplatin } \\
\text { Cyclophosphamide }\left(>1500 \mathrm{mg} / \mathrm{m}^{2}\right) \\
\text { Dacarbazine } \\
\text { Doxorubicin + Cyclophosphamide } \\
\text { Epirubicin + Cyclophosphamide }\end{array}$ & $\begin{array}{l}\text { Altretamine } \\
\text { Carmustine }\left(>250 \mathrm{mg} / \mathrm{m}^{2}\right) \\
\text { Mechlorethamine } \\
\text { Streptozocin }\end{array}$ \\
\hline Moderate emetogenic risk (emetic frequency: $30-90 \%$ ) & $\begin{array}{l}\text { Interleukin-2 }\left(>12-15 \text { million } \mathrm{IU} / \mathrm{m}^{2}\right) \\
\text { Busulfan }(>4 \mathrm{mg} / \text { day }) \\
\text { Carboplatin } \\
\text { Azacitidine } \\
\text { Cyclophosphamide }\left(\leq 1500 \mathrm{mg} / \mathrm{m}^{2}\right) \\
\text { Cytarabine }\left(>200 \mathrm{mg} / \mathrm{m}^{2}\right) \\
\text { Actinomycin } \mathrm{D} \\
\text { Bendamustine } \\
\text { Clofarabine } \\
\text { Daunorubicin } \\
\text { Doxorubicin } \\
\text { Epirubicin } \\
\text { Idarubicin } \\
\text { Ifosfamide } \\
\text { Interferon } \alpha\left(\geq 10 \mathrm{million} \mathrm{IU} / \mathrm{m}^{2}\right) \\
\text { Irinotecan } \\
\text { Melphalan }\left(\geq 50 \mathrm{mg} / \mathrm{m}^{2}\right)\end{array}$ & $\begin{array}{l}\text { Methotrexate }\left(\geq 250 \mathrm{mg} / \mathrm{m}^{2}\right) \\
\text { Oxaliplatin }\left(\geq 75 \mathrm{mg} / \mathrm{m}^{2}\right) \\
\text { Nedaplatin } \\
\text { Enocitabine } \\
\text { Therarubicin } \\
\text { Amrubicin } \\
\text { Arsenic trioxide } \\
\text { Temozolomide } \\
\text { Amifostine }\left(\geq 300 \mathrm{mg} / \mathrm{m}^{2}\right) \\
\text { Carmustine }\left(\leq 250 \mathrm{mg} / \mathrm{m}^{2}\right)\end{array}$ \\
\hline Low emetogenic risk (emetic frequency: $10-30 \%$ ) & $\begin{array}{l}\text { Interleukin-2 }\left(\leq 12 \text { million } \mathrm{IU} / \mathrm{m}^{2}\right) \\
\text { Brentuximab vedotin } \\
\text { Cytarabine }\left(100-200 \mathrm{mg} / \mathrm{m}^{2}\right) \\
\text { Cabazitaxel } \\
\text { Docetaxel } \\
\text { Liposomal doxorubicin } \\
\text { Etoposide } \\
\text { Eribulin } \\
\text { 5-Fluorouracil } \\
\text { Gemcitabine } \\
\text { Interferon- } \alpha\left(5-10 \mathrm{million} \mathrm{IU} / \mathrm{m}^{2}\right) \\
\text { Methotrexate }\left(50-250 \mathrm{mg} / \mathrm{m}^{2}\right) \\
\text { Mitomycin C }\end{array}$ & $\begin{array}{l}\text { Mitoxantrone } \\
\text { Nab-paclitaxel } \\
\text { Paclitaxel } \\
\text { Pemetrexed } \\
\text { Trastuzumab emtansine } \\
\text { Topotecan } \\
\text { Pentostatin } \\
\text { Nimustine } \\
\text { Ranimustine } \\
\text { Amifostine }(<300 \mathrm{mg}) \\
\text { Carfilzomib } \\
\text { Floxuridine } \\
\text { Ixabepilone } \\
\text { Omacetaxine } \\
\text { Pralatrexate } \\
\text { Romidepsin } \\
\text { Ziv-afibercept }\end{array}$ \\
\hline Minimal emetogenic risk (emetic frequency: $<10 \%$ ) & $\begin{array}{l}\text { L-Asparaginase } \\
\text { Alemtuzumab } \\
\text { Ipilimumab } \\
\text { Interferon- } \alpha\left(\leq 5 \text { million } \mathrm{IU} / \mathrm{m}^{2}\right) \\
\text { Ofatumumab } \\
\text { Bevacizumab } \\
\text { Bleomycin } \\
\text { Bortezomib } \\
\text { Cetuximab } \\
\text { Cladribine } \\
\text { Cytarabine }\left(<100 \mathrm{mg} / \mathrm{m}^{2}\right) \\
\text { Fludarabine } \\
\text { Gemtuzumab ozogamicin } \\
\text { Methotrexate }\left(\leq 50 \mathrm{mg} / \mathrm{m}^{2}\right) \\
\text { Temsirolimus } \\
\text { Trastuzumab } \\
\text { Nivolumab } \\
\text { Nelarabine } \\
\text { Panitumumab }\end{array}$ & $\begin{array}{l}\text { Peginterferon } \\
\text { Pertuzumab } \\
\text { Peplomycin } \\
\text { Ramucirumab } \\
\text { Rituximab } \\
\text { Vinblastine } \\
\text { Vincristine } \\
\text { Vinorelbine } \\
\text { Vindesine } \\
\text { Decitabine } \\
\text { Denileukin diftitox } \\
\text { Obinutuzumab } \\
\text { Dexrazoxane } \\
\text { Pegaspargase } \\
\text { Pembrolizumab } \\
\text { Siltuximab } \\
\text { Valrubicin } \\
\text { Liposomal vincristine }\end{array}$ \\
\hline
\end{tabular}

JSCO Japan Society of Clinical Oncology

*Agents in Italics are not approved for clinical practice use in Japan 
Table 2 Emetogenic risk category for oral chemotherapeutic agents

Table 3 Emetogenic risk category for radiation therapy

Table 4 Major updated issues in version 2

\begin{tabular}{lll}
\hline JSCO emetogenic risk category & Agent (regimen) & \\
\hline High emetogenic risk (emetic frequency: $>$ 90\%) & Procarbazine & \\
& Hexamethylmelamine & \\
Moderate emetogenic risk (emetic frequency: 30-90\%) & Cyclophosphamide & Imatinib \\
& Temozolomide & Crizotinib \\
& Trifluridine-tipiracil & Vinorelbine \\
Low emetogenic risk (emetic frequency: 10-30\%) & Alectinib & S-1 \\
& Capecitabine & Sunitinib \\
& Etoposide & Lapatinib \\
& Everolimus & Lenalidomide \\
& Fludarabine & \\
& Tegafur-Uracil (UFT) & \\
Minimal emetogenic risk (emetic frequency: $<10 \%)$ & Thalidomide & Erlotinib \\
& Gefitinib & Methotrexate \\
& Hydroxyurea & Sorafenib \\
& Melphalan & Chlorambucil \\
& & 6-Thioguanine \\
\hline
\end{tabular}

JSCO Japan Society of Clinical Oncology

*Agents in Italics are not approved for clinical practice use in Japan

\begin{tabular}{lll}
\hline JSCO emetogenic risk category & Treated area & \\
\hline High emetogenic risk (emetic frequency: $>90 \%$ ) & Total body & \\
Moderate emetogenic risk (emetic frequency: 30-90\%) & Upper abdomen & \\
Low emetogenic risk (emetic frequency: 10-30\%) & Lower thorax & Pelvis \\
& Cranium (radiosurgery) & Craniospinal \\
Minimal emetogenic risk (emetic frequency: $<10 \%)$ & Head and neck & Extremities \\
& Cranium & Breast \\
\hline
\end{tabular}

No description changes were added in the second version

JSCO Japanese Society of Clinical Oncology

\begin{tabular}{ll}
\hline Major updated issues & \\
\hline 1 & Changes in emetogenic risk categorization for anti-cancer agents (Tables 1, 2) \\
2 & Description regarding olanzapine usage (described in CQ2 and CQ3) \\
3 & Description regarding steroid sparin (described in CQ2 and CQ3) \\
4 & Adverse drug reactions of antiemetic drugs (Table 5) \\
\hline
\end{tabular}

(4) List of adverse toxicities for antiemetic agents (Table 5).

(1) The JSCO antiemetic guideline committee provided revised tables on emetogenic risk categorization for intravenous and oral anti-cancer agents (Tables 1,2,3), listing new chemotherapeutic agents, such as molecular or immunotherapeutic agents, according to emetogenicity as described in studies and drug interview forms.

(2) Studies have shown that olanzapine, a multi-acting receptor-targeted antipsychotics (MARTA), was effec- tive in controlling late-onset nausea and vomiting associated with high- and moderate-risk anti-cancer drugs [11-16], which has been described mainly in CQ2 and CQ3.

(3) To reduce the adverse effects of steroids, an administration method that does not use steroids on day 2-3 of AC therapy (i.e., steroid-sparing) was used. Indeed, phase III studies have shown that steroid-sparing was not inferiority to conventional steroids use, with other reports also showing the effects of steroid-sparing [1720] (CQ2 and CQ3).

(4) To perform the proper antiemetic therapy using antiemetic agents, adverse effects of these agents should 
be taken into consideration to explain for patients by medical staffs. The adverse toxicities for antiemetic agents were listed in Table 5 for 'at a glance'.

\section{Clinical questions and recommendations}

The working group of the JSCO antiemetic guideline adopted clinical questions (CQs) as the guideline format similar to that in the first version wherein $21 \mathrm{CQs}$ were described. In the second version, however, the number of CQs was reduced to 18 . Moreover, the second version revised the title and context of $\mathrm{CQ} 4$ from the first version while adding three new CQs (i.e., CQ11, CQ12, and CQ13). When no changes in the description of the CQs from the first version were present, a short discussion indicating such was added as the last line of each CQ.

The following are the CQs included herein:

CQ1. How should oral chemotherapeutic agent-induced nausea and vomiting be managed?

CQ2. How should cancer chemotherapy-induced acute nausea and vomiting be prevented?

CQ3. How should delayed nausea and vomiting after cancer chemotherapy be prevented?

CQ4. How do we use a second-generation serotonin $\left(5-\mathrm{HT}_{3}\right)$ receptor antagonist?

CQ5. Are corticosteroids recommended for preventing nausea and vomiting?

CQ6. How should breakthrough nausea and vomiting be managed?

CQ7. How should lowly and minimally emetogenic chemotherapy-induced acute nausea and vomiting be managed?

CQ8. How is nausea and vomiting managed for particular regimens, such as multiple daily administrations of cisplatin?

CQ9. How should anticipatory nausea and vomiting be managed?

CQ10. How are emetogenic risks categorized for radiation therapy?

CQ11. What factors are associated with nausea and vomiting?

CQ12. How are antiemetic treatment effects evaluated?

CQ13. How should CINV among patients staying at home be managed?

CQ14. How should CINV among pediatric patients with malignancies be managed?

CQ15. Can nausea be differentiated from anorexia, pyrosis, and dyspepsia?

CQ16. How are various forms of agents appropriately selected and used?

CQ17. Which antiemetic drugs produce pharmacokinetic interactions?

CQ18. How should opioid-induced nausea and vomiting be managed?
CQ1. How should oral chemotherapeutic agent-induced nausea and vomiting be managed?

Recommendation (Grade C1): According to clinical study protocols designed to assess the efficacy of supportive cotreatments, suspension and/or dose reduction of chemotherapeutic agents should be considered to control at most grade 2 nausea and vomiting.

Emetogenic risks of oral chemotherapeutic agents are presented in Table 5. In Japan, oral fluoropyrimidine-based regimens have been frequently used as an adjuvant treatment to tegafur-uracil/leucovorin and capecitabine for colorectal cancer, S-1 for gastric cancer, and tegafur-uracil for breast and lung cancers, with multiple clinical trials demonstrating reasonable efficacy. Moreover, Japanese clinical practice guidelines have indicated that S-1 and tegafur-uracil/ leucovorin are effective agents for advanced gastric and colorectal cancers. Although these oral chemotherapeutic agents have lower emetogenicity when administered alone, adverse digestive events have been found to occur following repeated daily administration. Hence, antiemetic treatments are important to achieve higher drug adherence and optimize treatment effects.

The 2015 NCCN guidelines recommend the daily administration of metoclopramide, prochlorperazine, haloperidol, etc. (including lorazepam and $\mathrm{H}_{2}$ receptor antagonists if necessary) as oral agents, including drugs with moderate and minimal risk.

Randomized control studies showing the efficacy of these oral anticancer drugs generally provided antiemetic treatments to patients when grade 2 nausea/vomiting. When such cannot to be controlled by antiemetic treatments, suspending administration and/or dose reduction was commonly observed.

\section{CQ2. How should cancer chemotherapy-induced acute nausea and vomiting be prevented?}

Recommendation (Grade A): A triple regimen consisting of neurokinin $1\left(\mathrm{NK}_{1}\right)$ receptor antagonist (aprepitant), serotonin (5-hydroxytryptamine: $5-\mathrm{HT}_{3}$ ) receptor antagonist, and dexamethasone is recommended for acute emesis during highly emetogenic cancer chemotherapy.

Recommendation (Grade A): Regimens containing 5- $\mathrm{HT}_{3}$ receptor antagonists and dexamethasone are generally recommended for acute emesis during moderately emetic cancer chemotherapy. For certain chemotherapy regimens, the addition of $\mathrm{NK}_{1}$ receptor antagonists to $5-\mathrm{HT}_{3}$ receptor antagonist and dexamethasone regimens have been considered.

Acute onset nausea and vomiting occurs within a few minutes to several hours, with the intensity generally peaking within 5-6 h after chemotherapy administration and 
recovery usually taking place within $24 \mathrm{~h}$. Considering that the unfavorable side effects of nausea and vomiting are associated with poor treatment adherence and effects, CINV management has been considered essential for successful cancer chemotherapy. In addition, incomplete prevention of acute emesis may lead to uncontrollable delayed emesis [21]. Hence, according to the four emetogenic risk categories indicated in CQ2 and CQ3, appropriate antiemetic treatments are needed upon initiating chemotherapy. The standard model for antiemetic treatment regimens is detailed in the four diagrams of Fig. 1. In the high emetogenic risk diagram, evidence for the antiemetic action of AC regimens, which was obtained from clinical trials of other high emetic cancer agents, suggested no additional effects of dexamethasone after day 2. Upon publication of the first guideline, oral aprepitant had been the only $\mathrm{NK}_{1}$ receptor antagonist available for clinical use in Japan. Subsequently, the Japanese Ministry of Health, Labour and Welfare had approved the use of fosaprepitant, an intravenous $\mathrm{NK}_{1}$ receptor antagonist, in November 2011. Accordingly, the diagram had been immediately modified to included additional information regarding fosaprepitant as a minor revision to the guideline.

(1) High emetogenic risk

Aprepitant (or fosaprepitant) in combination with a $5-\mathrm{HT}_{3}$ receptor antagonist and dexamethasone is recommended for high-risk anticancer drugs as recommended by guidelines produced with a high level of consensus.

A triple combination consisting of oral $\mathrm{NK}_{1}$ receptor antagonist aprepitant $(125 \mathrm{mg}$ ) or intravenous fosaprepitant $(150 \mathrm{mg})$, a $5-\mathrm{HT}_{3}$ receptor antagonist, and $12 \mathrm{mg}$ of dexamethasone (injectable: $9.9 \mathrm{mg}$ ) is recommended. Studies have shown that the combined use of the aforementioned three agents with aprepitant promoted better antiemetic activity compared to the conventional combination of a $5-\mathrm{HT}_{3}$ receptor antagonist and dexamethasone [22-24]. One study found that fosaprepitant was not inferiority to aprepitant in combination with ondansetron and dexamethasone for cisplatin therapy [25].

While palonosetron, a second-generation $5-\mathrm{HT}_{3}$ receptor antagonist, had the same preventive effect on acute emesis as other drugs following direct comparisons between single agents and in combination with dexamethasone, it was found to be superior in the prevention of delayed emesis [26, 27] (CQ3). In two-drug combinations with a conventional $5-\mathrm{HT}_{3}$ receptor antagonist, dexamethasone (CQ5) had been provided at a dose of 16-20 mg (injectable 13.2-16.5 mg). However, the area under the concentration-time curve (AUC) for dexamethasone increases when combined with aprepitant due to the latter's influence on CYP3A4, thereby requiring a dose reduction to $12 \mathrm{mg}$ (injectable $9.9 \mathrm{mg}$ ) for triple combinations. Although aprepitant is usually administered over 3 days, insufficient effects could prompt additional administration up to 5 days.
The 2015 NCCN guideline recommends the MARTA olanzapine (10 mg orally, days $1-4)$ instead of aprepitant in combination with palonosetron and dexamethasone. Indeed, the results of a phase III randomized controlled trial showed that olanzapine was equivalent to aprepitant in combination with palonosetron and dexamethasone for highly emetogenic anticancer drugs, such as cisplatin and AC agents [16]. However, the used of olanzapine in Japan requires considerable care due to adverse events, such as sleepiness and glucose intolerance. Other options, including lorazepam, $\mathrm{H}_{2}$ receptor antagonists, or a proton pump inhibitor may be additionally used depending on the situation (Fig. 1 and Diagram 1).

(2) Moderate emetogenic risk

For moderately risk anticancer drugs, a combination of 5- $\mathrm{HT}_{3}$ receptor antagonists and dexamethasone is recommended. For specific anticancer drug regimens, aprepitant can be added according to each patient's condition.

Although a combination of $5-\mathrm{HT}_{3}$ receptor antagonists and dexamethasone (8-12 mg; injectable: 6.6-9.9 mg) has generally been used, aprepitant $(125 \mathrm{mg})$ has been recommended in combination with some anticancer drugs (carboplatin, ifosfamide, irinotecan, methotrexate, etc.). In such cases, the dose of dexamethasone is reduced to $4-6 \mathrm{mg}$ (injectable drug: 3.3-4.95 mg) (Fig. 1 and Diagram 2).

A phase III multicenter randomized controlled trial in Japan including patients with colorectal cancer receiving oxaliplatin-based chemotherapy revealed that those who received aprepitant/fosaprepitant in combination with $5-\mathrm{HT}_{3}$ receptor antagonists and dexamethasone had better nausea and vomiting control during the overall and delayed phase compared to those who received a combination of $5-\mathrm{HT}_{3}$ receptor antagonists and dexamethasone [28].

(3) Low emetogenic risk (CQ7)

A single 4- to 8-mg dose of dexamethasone (injectable: $3.3-6.6 \mathrm{mg}$ ) is recommended for lowly emetogenic anticancer agents. Furthermore, depending on circumstances, prochlorperazine or metoclopramide can also be used (Fig. 1 and Diagram 3).

(4) Minimal emetogenic risk

Antiemetics have been deemed unnecessary for minimal risk anticancer agents (Figs. 1 and 3).

\section{CQ3. How should delayed nausea and vomiting after cancer chemotherapy be prevented?}

Recommendation (Grade A): A combined regimen consisting of $\mathrm{NK}_{1}$ receptor antagonist (aprepitant) and dexamethasone is recommended for treating delayed emesis during highly emetogenic cancer chemotherapy.

Recommendation (Grade A): A single administration of dexamethasone is basically recommended for delayed emesis during moderately emetic cancer chemotherapy. In 
Fig. 1 Diagram of antiemetic treatments for intravenous cancer chemotherapy

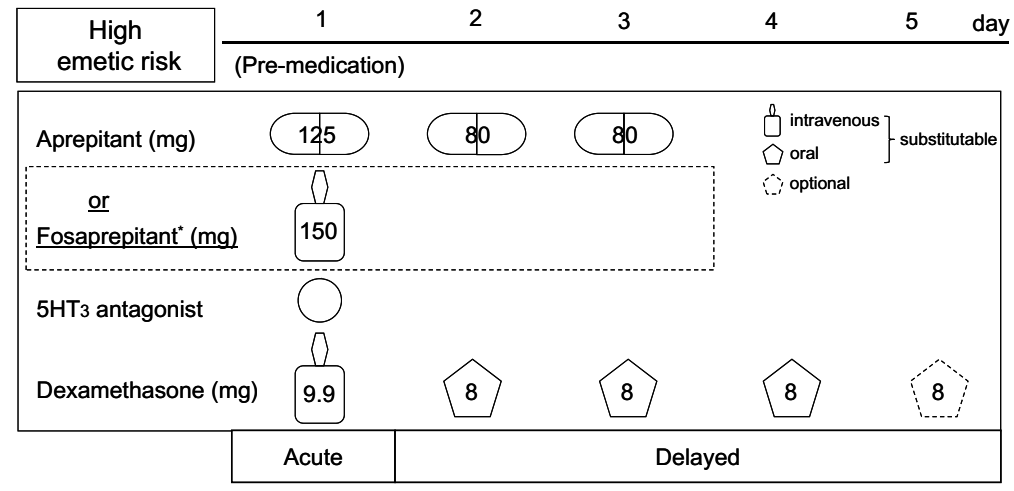

Diagram1. High emetogenic risk: In the absence of aprepitant, 13.2-16.5 mg of dexamethasone should be given on day 1

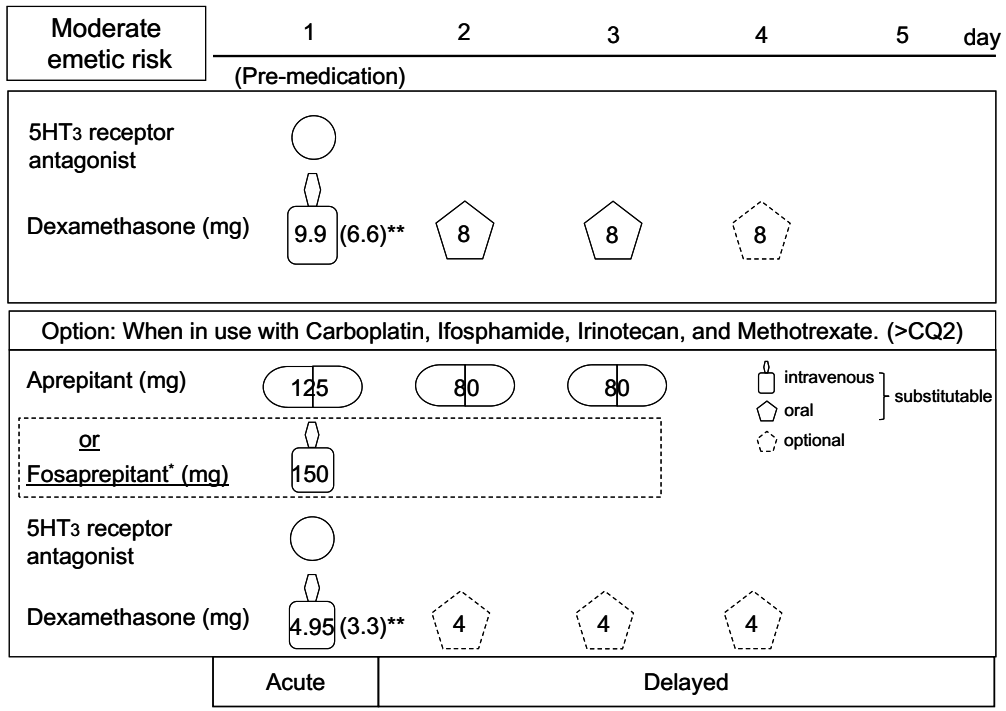

Diagram 2. Moderate emetogenic risk

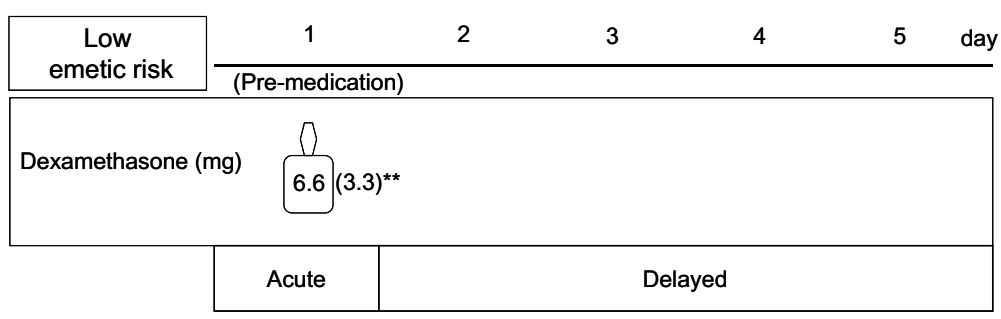

\begin{tabular}{|c|ccccc|}
\hline $\begin{array}{c}\text { Minimal } \\
\text { emetic risk }\end{array}$ & 1 & 2 & 3 & 4 & 5 \\
\hline & & \\
\hline
\end{tabular}

\section{Diagram 3. Low/Minimal emetogenic risk}

* Optional fosaprepitant was added to the diagrams from a revised edition version 1.2. ** Optional dose of dexamethasone

The diagrams indicate standard examples of antiemetic treatment regimens. Flexible modifications are necessary according to specific conditions of each patient.

Intravenous dexamethasone includes $3.3 \mathrm{mg} / \mathrm{mL}$ of dexamethasone out of a total 4 $\mathrm{mg} / \mathrm{mL}$ of dexamethasone sodium phosphate. 
Table 5 Adverse drug reactions of the antiemetic agents

$5-\mathrm{HT}_{3}$ receptor antagonists

Azasetron, Indisetron, Ondansetron, Granisetron, Tropisetron, Ramosetron, Palonosetron

Main adverse drug reaction

Mental nervous system

Digestive organ

Infrequent but severe reaction

Immune system

$\mathrm{NK}_{1}$ receptor antagonists:

Circulatory organ

Headache

Constipation

Aprepitant, fosaprepitant

Main adverse drug reaction

Mental nervous system

Headache

Digestive organ

Constipation

Respiratory

Hiccups

Infrequent but severe reaction

Injection site (fosaprepitant)

Skin

Immune system

Injection site pain

Dexamethasone

Main adverse drug reaction

Immune system

Mental nervous system

Infrequent but severe reaction

Metabolism

Stevens-Johnson syndrome

Phenothiazines:

Metoclopramide, Prochlorperazine

Infrequent but severe reaction

Mental nervous system

Latent dyskinesia

Malignant syndrome

Benzodiazepines:

Lorazepam

Main adverse drug reaction

Mental nervous system

Sleepiness, dizziness

$\mathrm{H}_{2}$ receptor antagonists:

Cimetidine, Nizatidine, Famotidine, Ranitidine, Lafutidine, Loxatidine

Main adverse drug reaction

Mental nervous system

Headache

Digestive organ

Infrequent but severe reaction

Skin

Immune system

Constipation, diarrhea

Stevens-Johnson syndrome

Proton pump inhibitors:

Esomeprazole, Omeprazole, Rabeprazole, Lansoprazole

Main adverse drug reaction

Mental nervous system

Digestive organ

Infrequent but severe reaction

Skin

Immune system

Genitourinary system

Diarrhea/loose stools, abdominal pain

Stevens-Johnson syndrome, toxic epidermal necrolysis (TEN)

Shock, anaphylaxis

Interstitial nephritis some cases, regimens comprising $\mathrm{NK}_{1}$ antagonists and/or dexamethasone can be considered.

Delayed onset of nausea and vomiting has been shown to occur more than $24 \mathrm{~h}$ after chemotherapy administration. Under these circumstances, control of delayed emesis is essential for maintaining patients' quality of life, motivation for further treatment, and mental health. In specific cases requiring dexamethasone restriction, 2-4 days of 5-HT antagonist is recommended instead of dexamethasone.

(1) High emetogenic risk
For delayed vomiting with highly emetogenic anticancer drugs, a combination of $\mathrm{NK}_{1}$ receptor antagonist aprepitant and dexamethasone is recommended.

Randomized controlled trials and pooled results have shown that a combination of 4-8 $\mathrm{mg}$ of oral dexamethasone (days 2-3) and $80 \mathrm{mg}$ of oral aprepitant (days 2-3), an $\mathrm{NK}_{1}$ receptor antagonist, is better useful than dexamethasone alone [29-32]. Moreover, this two-drug combination can better suppress delayed emesis compared to a combination of $5-\mathrm{HT}_{3}$ receptor antagonists and dexamethasone $(21 \%$ vs. $36 \% ; p<0.001$ ) [33]. 
Highly emetogenic regimens containing anthracycline anticancer drugs and cyclophosphamide differ from those utilized in clinical trials. Available evidence on AC therapy has yet to prove that dexamethasone had an effect on days 2 and 3 [17]. Furthermore, for the purpose of reducing side effects of steroids, overseas phase III trials have shown that steroid-sparing methods, which eliminate the use of steroids on days 2-3 of AC therapy, was not inferior to regular steroid use $[17,18,20]$. However, reports have also found that steroids are effective from days 2 to 3 [19]. As such, no consensus has yet been reached on steroid-sparing according to clinical trials in 2015 (CQ5).

\section{Commentary}

Recent evidence from Japan in the form of a phase III study (TRIPLE trial) comparing the antiemetic effects of palonosetron, dexamethasone, and aprepitant in combination with granisetron, dexamethasone, and aprepitant for highly emetogenic anticancer drug administration revealed that the palonosetron group, although not the primary endpoint, significantly suppressed nausea and vomiting in the late phase [34].

Another Japanese phase III study (WJOG 6811 B trial) that compared granisetron and palonosetron in combination with dexamethasone/fosaprepitant for a regimen containing anthracycline and cyclophosphamide for breast cancer reported that the palonosetron group was significantly associated with nausea and vomiting in the delayed phase [35].

(2) Moderate emetogenic risk

For delayed emesis with moderately emetic anticancer drugs, dexamethasone is used alone. Depending on the case, a combination of aprepitant and dexamethasone or $5-\mathrm{HT}_{3}$ receptor antagonists is used.

Studies have found that antiemetic regimens in combination with $5-\mathrm{HT}_{3}$ receptor antagonists or dexamethasone provided no advantage compared to monotherapy [36, 37]. Hence, the cost-effectiveness of $5-\mathrm{HT}_{3}$ receptor antagonists has remained controversial (palonosetron was not included in this review) [38].

However, in cases where dexamethasone cannot be used due to hepatitis, etc., $5-\mathrm{HT}_{3}$ receptor antagonists may be used. Furthermore, results of a phase III study suggested that administration of palonosetron alone was sufficient for controlling delayed emesis [39]. Thus, the use of palonosetron alone can be one of the options for late emesis at present. Moreover, some phase III trials have shown that $5-\mathrm{HT}_{3}$ receptor antagonists and corticosteroids have equivalent antiemetic and QOL improving effects [40].

The 2015 NCCN guideline and clinical trials have also indicated that aprepitant along or in combination with dexamethasone was efficacious for delayed emesis [1, 41].

(3) Low emetogenic risk/minimal emetogenic risk
Antiemetics are generally not recommended for mild and minimal risk anticancer drugs, with no randomized controlled trials having been conducted on the same (see Fig. 1 and Diagram 3).

\section{CQ4. How do we use a second-generation serotonin $\left(5-\mathrm{HT}_{3}\right)$ receptor antagonist?}

Recommendation (Grade C1): Second-generation 5- $\mathrm{HT}_{3}$ receptor antagonists are preferred when used in the following context: $\mathrm{NK}_{1}$ receptor antagonist $+5-\mathrm{HT}_{3}$ receptor antagonist (day 1)+ dexamethasone (days 1-4) as prophylaxis for CINV during highly emetogenic chemotherapeutic regimens (except with cisplatin less than $50 \mathrm{mg} / \mathrm{m}^{2}$ and CHOP therapy).

Recommendation (Grade $\mathrm{C} 1$ ): As prophylaxis for CINV during MEC, especially when using a relatively highly emetogenic anticancer drugs, first-generation $5-\mathrm{HT}_{3}$ receptor antagonists are recommended when $\mathrm{NK}_{1}$ receptor antagonists are used. In the absence of $\mathrm{NK}_{1}$ receptor antagonists, second-generation $5-\mathrm{HT}_{3}$ receptor antagonists are preferred.

Several $5-\mathrm{HT}_{3}$ receptor antagonists have currently been available in Japan, with their efficacy in managing CINV having been demonstrated, particularly under conditions of acute-phase emesis. However, the efficacy of such agents in the treatment of delayed emesis has remained controversial given the absence of further antiemetic effects of additional treatments after the initial occupation of the $5-\mathrm{HT}_{3}$ receptors with antagonistic agents.

The TRIPLE trial, which compared the antiemetic effects of a palonosetron, dexamethasone, aprepitant arm with a granisetron, dexamethasone, and aprepitant arm for cisplatin-containing highly emetogenic chemotherapeutic regimen, showed that the palonosetron arm significantly suppressed delayed nausea and vomiting, though not the primary endpoint [34]. For less than $50 \mathrm{mg} / \mathrm{m}^{2}$ of cisplatin and CHOP regimen, evidence has shown that second-generation $5-\mathrm{HT}_{3}$ receptor antagonists were no superior to firstgeneration ones.

When using an $\mathrm{AC}$ regimen without $\mathrm{NK}_{1}$ receptor antagonists, palonosetron was proven to be not inferior to granisetron during the acute phase but superior to granisetron during the delayed phase [27].

The SENRI trial [28] revealed that triple antiemetic therapy comprising a $\mathrm{NK}_{1}$ receptor antagonist, $5-\mathrm{HT}_{3}$ receptor antagonist, and dexamethasone was superior to double therapy comprising a $5-\mathrm{HT}_{3}$ receptor antagonist and dexamethasone in suppressing vomiting rates during oxaliplatinbased MEC regimen.

Furthermore, triple antiemetic therapy had been found to be superior to double therapy comprising a $5-\mathrm{HT}_{3}$ receptor antagonist and dexamethasone in a subset analysis of a 
randomized study for antiemetic therapy using a MEC regimen [41].

No conclusive results have been available to elucidate the difference in efficacy between first- and second-generation $\mathrm{NK}_{1}$ receptor antagonists during MEC regimens.

\section{CQ5. Are corticosteroids recommended for preventing nausea and vomiting?}

Recommendation (Grade A): Corticosteroids is an effective antiemetic agent at recommended doses, which are determined according to the emetogenic risk categories of chemotherapeutic regimens.

Although corticosteroids have been used as prophylaxis against emesis during cancer chemotherapy for 25 years [42], their mechanism of action remains unclear compared to those of 5- $\mathrm{HT}_{3}$ and $\mathrm{NK}_{1}$ antagonists, which have recently been approved with clear details regarding their mechanisms. Although multiple classes of corticosteroid are available, dexamethasone and methylprednisolone have been most frequently used antiemetics, with strong evidence supporting their effects $[43,44]$. However, the efficacy of high dose dexamethasone has yet to be compared with $20-\mathrm{mg}$ treatments in either Western [43, 44] or Japanese populations [45].

\section{CQ6. How should breakthrough nausea and vomiting be managed?}

Recommendation (Grade B): Fixed, around-the-clock administration of various drugs should be considered according to the patient symptoms. In addition, antiemetic $5-\mathrm{HT}_{3}$ receptor antagonists should be replaced with another drug of the same type.

Breakthrough nausea and vomiting are defined as the continuous onset of nausea and vomiting even after prophylactic administration of antiemetics.

A systematic review of antiemetic treatments in patients with advanced cancer showed that metoclopramide was superior to placebo and equivalent to ondansetron, although response rates were only $23-36 \%$ for nausea and $18-52 \%$ for vomiting, respectively [46]. Moreover, a randomized clinical trial including patients with advanced cancer showed that additional dexamethasone for nausea following the failure of antiemetic responses to metoclopramide had no significant effects [47].

\section{CQ7. How should lowly and minimally emetogenic chemotherapy-induced acute nausea and vomiting be managed?}

Recommendation (Grade B): During lowly emetogenic chemotherapy, dexamethasone should be considered according to the chemotherapeutic regimen and patient background.

Recommendation (Grade C1): Routine usage of dexamethasone is not recommended for minimally emetogenic chemotherapy.

Prophylactic antiemetic treatment is not recommended for lowly or minimally emetogenic chemotherapy. Nonetheless, some patients suffer from emesis during treatment with lowly/minimally emetogenic chemotherapies, necessitating flexible and appropriate treatment despite the absence of high-level evidence. The ASCO and MASCC/ ESMO antiemetic guidelines have recommended the administration of 4-8 $\mathrm{mg}$ of dexamethasone [5, 6] and inclusion of prochlorperazine [48] and metoclopramide as optional antiemetics.

No descriptions were changed in the second version.

\section{CQ8. How is nausea and vomiting managed for particular regimens, such as multiple daily administrations of cisplatin?}

Recommendation (Grade B): A triple antiemetic regimen comprising 5- $\mathrm{HT}_{3}$ antagonists, dexamethasone, and aprepitant is recommended for preventing acute nausea and vomiting during cisplatin-containing chemotherapeutic regimens. Meanwhile, a double regimen comprising dexamethasone and aprepitant is recommended for delayed nausea and vomiting, even during regimens involving multiple daily cisplatin administrations.

Cisplatin, which has been widely accepted as a highly emetogenic chemotherapeutic agent, is commonly administered every 3 or 4 weeks at $\geq 50 \mathrm{mg} / \mathrm{m}^{2}$ for the treatment of various malignancies. However, differing cisplatin regimens have been established with reasonable supporting evidence, including multiple daily cisplatin doses at $<50 \mathrm{mg} / \mathrm{m}^{2}$ for cholangiocarcinomas, bladder cancer, and germinomas [49, $50]$ and continuous cisplatin injections at $100 \mathrm{mg} / \mathrm{m}^{2}$ over 4 days for non-Hodgkin lymphomas.

No descriptions were changed in the second version.

\section{CQ9. How should anticipatory nausea and vomiting be managed?}

Recommendation (Grade B): Initially, complete prevention of emesis is essential during the acute and delayed phases so that patients never experience nausea and vomiting.

Recommendation (Grade B): Benzodiazepine is effective for anticipatory nausea and vomiting.

Recommendation (Grade B): Psychological therapies, such as systematic desensitization/behavioral treatment, 
relaxation therapy, and hypnotherapy for pediatric patients, effectively ameliorate anticipatory nausea and vomiting.

Anticipatory nausea and vomiting have been found to occur immediately prior to treatment and reflects previous negative experiences of cancer chemotherapy [51-53], although nausea is more common than vomiting among such cases. The ideal prophylaxis for this symptom is to perform complete emesis prevention upon commencement of treatment [52-55].

No descriptions were changed in the second version.

\section{CQ10. How are emetogenic risks categorized for radiation therapy?}

Recommendation (Grade A): Emetogenic risks of radiation therapy are classified according to tissue targets and volumes for irradiation.

The risk of radiation-induced nausea and vomiting is categorized according to the percentage of patients with emesis. Moreover, the whole body and upper abdominal radiation therapy are likely to cause greater emesis, with the frequency of nausea and vomiting increasing with larger total doses and target tissue volumes [56, 57].

No descriptions were changed in the second version.

\section{CQ11. What factors are associated with nausea and vomiting?}

Recommendation (Grade C1): Treatment and patient factors influence the emetogenic risks of CINV. Treatment factors include emetogenicity and dosages of chemotherapeutic agents, tissue target, and radiation therapy volume, while relevant patient factors include age, gender, and alcohol consumption.

Patient factors, such as age [58], gender [58, 59], alcohol consumption [60], and experience of nausea gravidarum, have been shown to influence the emetogenicity of CINV. The 2015 NCCN guideline also shows that bowel obstruction, vestibulopathy, brain metastasis, electrolyte abnormality, uremia, opioid use, gastric atony, and mental disorders are potential risk factors for emesis. Treatment-related factors are classified into risk categories, with the antiemetics recommended for each category being fixed. However, no current consensus exists on how to deal with patient-related factors.

The CINV Study Group of Japan performed a survey evaluating the incidence of acute and delayed nausea/vomiting caused by highly and moderately emetogenic anticancer drugs [61]. In this survey, gender (female) and age (young) were identified as factors influencing CINV during the acute phase, while gender (female) was identified as a factor during the delayed phase.

\section{CQ12. How are antiemetic treatment effects evaluated?}

Recommendation (Grade A): Antiemetic treatment effects should be assessed at every visit for outpatients and within $24 \mathrm{~h}$ after administration of chemotherapy for admitted patients.

Recommendation (Grade C1): Strict assessments require patients to report their conditions to medical staff using selfreporting systems.

Recommendation (Grade C1): Continuous assessments will be performed from baseline (before treatment) and throughout the course of treatment for appropriate palliation of CINV.

No clear consensus or evidence has been available regarding the evaluation of nausea and vomiting among patients with cancer, as well as antiemetic use. Identifying the cause of emesis through clinical evaluation is important (CQ14 and CQ16). The common terminology criteria for adverse events (CTCAE) may be useful in evaluating side effects during chemotherapy, which are based on objective assessments by medical staff rather than subjective assessments by patients.

Applicable patient-directed subjective evaluations include the numerical rating scale (NRS), visual analog scale (VAS), verbal rating scale, and the Wong-Baker Face Rating Scale [62]. Moreover, the Index of Nausea, Vomiting and Retching [63], MASCC Antiemesis Tool [64], Morrow Assessment of Nausea And Emesis [65], and Functional Living Index-Emesis scores [66] may also be utilized as tools for evaluating changes in emesis and ensuing influences on quality of life.

\section{CQ13. How should CINV among patients staying at home be managed?}

Recommendation (Grade C1): Despite the lack of recommended treatments, management of nausea and vomiting during home treatment is important. Hence, treatment based on evidence is performed.

For outpatients, managing nausea/vomiting at home, which may be out of the medical staff's reach, is an important issue directly linked to patients' QOL. Some reports have suggested that patients want to prioritize the control of delayed-phase nausea in practice $[67,68]$. Accordingly, Tamura et al. reported that Japanese patients with cancer receiving chemotherapy were more concerned regarding delayed CINV than acute CINV [61]. However, medical staff have no definitive methods for evaluating CINV among patients staying at home after chemotherapy. No clinical trials regarding the effective treatment for delayed CINV, especially focusing on nausea and vomiting at home, had been identified. Hence, further studies concerning CINV at home are needed. 


\section{CQ14. How should CINV be managed among pediatric patients with malignancies?}

Recommendation (Grade C1): Multidisciplinary management using $5-\mathrm{HT}_{3}$ receptor antagonists, corticosteroids, and other antiemetic agents can control CINV, even among pediatric patients.

More than $70 \%$ of cancer among children are currently curable with modern and intensive therapeutic modalities, including high-dose chemotherapy with or without allogeneic stem cell transplantation. However, only a few reports have presented high-level evidence regarding antiemetic treatment among pediatric patients from Western populations [69-71]. Accordingly, such patients receive modified dosages based on the results of clinical trials among adult patients. Proper antiemetic treatments may allow pediatric patients to receive cancer chemotherapy without a decline in QOL.

CQ15. Can nausea be differentiated from anorexia, pyrosis, and dyspepsia? Which diseases produce symptoms of nausea and vomiting?

Recommendation (Grade B): No definitive evidence allows for the differentiation between nausea and anorexia, pyrosis, and dyspepsia. However, proton pump inhibitors (PPI) and $\mathrm{H}_{2}$ blockers are recommended for patients with these symptoms.

Recommendation (Grade C1): Antiemetic agents should be used according to accurate assessments of patient condition.

Symptoms of anorexia, pyrosis, and dyspepsia are caused by multiple factors related to digestive dysfunction and are frequently accompanied by nausea and other symptoms. Therefore, chemotherapy-induced nausea has not been strictly differentiated from other symptoms of digestive dysfunction. Nonetheless, PPI and $\mathrm{H}_{2}$ blockers are recommended as optional treatments for these symptoms [72].

In addition to treatments for CINV, patients with malignancies may suffer from nausea and vomiting due to the following conditions:

Partial or complete bowel obstruction.

Vestibulopathy.

Brain metastasis.

Electrolyte abnormality (hypercalcemia, hyponatremia, and hyperglycemia).

Uremia.

Other combinations of drugs, including opioids.

Gastric atony.

Anticipatory nausea and vomiting.

No descriptions were changed in the second version.
CQ16. How are various forms of agents appropriately selected and used?

Recommendation (Grade B): Patients should self-manage the use of oral agents. Considering that nausea and vomiting prevent patients from taking oral treatments, optional intravenous administration should be considered.

A meta-analysis of randomized control trials showed that oral and intravenous 5- $\mathrm{HT}_{3}$ receptor antagonists had similar effects [73]. Oral agents may have superior cost-effectiveness and convenience compared to intravenous agents, particularly when administered as tablets that disintegrate orally. On the other hand, intravenous agents may improve treatment adherence among pediatric patients.

\section{CQ17. Which antiemetic drugs produce pharmacokinetic interactions?}

Recommendation (Grade B): Aprepitant/fosaprepitant should be used carefully to avoid interactions with coadministered drugs, including certain chemotherapeutic agents.

Aprepitant acts as a substrate that induces and inhibits cytochrome P450 enzymes 3A4 (CYP3A4) and 2C9 (CYP2C9). Hence, aprepitant can alter plasma concentrations of co-administered drugs by interacting with these critical drug-metabolizing enzymes [74]. Chemotherapeutic agents that are metabolized by CYP3A4 include docetaxel, paclitaxel, etoposide, irinotecan, ifosfamide, imatinib, vinorelbine, vinblastine, and vincristine. Although doses for several chemotherapeutic agents used concurrently with aprepitant in phase III trials were not adjusted, such drugs should be used with caution $[75,76]$ given that aprepitant interacts with several non-chemotherapeutic drugs, including warfarin, dexamethasone, and methylprednisolonre [77]. Concurrent use of aprepitant temporarily reduces prothrombin time-international normalized ratio among patients receiving regimens containing warfarin, necessitating anticoagulant monitoring among these patients [29]. Aprepitant also increases the AUCs of corticosteroids dexamethasone, and methylprednisolone, necessitating appropriate reductions in corticosteroid doses (CQ7) [74]. However, to ensure anticancer effects, corticosteroid doses in chemotherapeutic regimens for malignant lymphoma should not be reduced, despite concomitant use of aprepitant.

No descriptions were changed in the second version.

\section{CQ18. How should opioid-induced nausea and vomiting be managed?}

Recommendation (Grade C1): Prophylactic antiemetic treatments using dopamine receptor antagonists for 
approximately 7 days during opioid therapy may be useful despite the lack of high-level evidence of efficacy and safety.

The World Health Organization ladder strongly recommends opioid use for cancer pain according to high-level evidences of efficacy and safety. Among the three opioid receptors, the $\mu$ and $\kappa$ receptors are categorized as emetogenic, while the $\delta$ receptor exhibits antiemetic functions.

Patients frequently suffer from constipation, sleepiness, nausea, and vomiting upon initiation of opioid therapy. However, antiemetic treatments for opioid-induced emesis comprising dopamine receptor antagonist for 7 days (considering the side effects of dopamine receptor antagonists) may be important for successful pain control among patients with cancer, despite the lack of high-level evidence of efficacy and safety. Moreover, the differential diagnosis of other causes is important for patients suffering from emesis after opioid treatments.

\section{Adverse drug reactions of antiemetic agents}

Adverse drug reactions of antiemetic agents have been considered obstacles hindering appropriate antiemetic therapies among patients with cancer. The update committee for the second version considered that information related to the adverse reaction of antiemetic drugs should be made available to patients with cancer, a list of which is presented in Table 5.

\section{Discussion}

Excellent and up-to-date cancer medical practitioners select appropriate medications based on the optimal course of treatment and safely maintain the therapeutic intensity while minimizing pain and sequelae leading to the maximum effect. With the establishment of treatment guidelines for various cancers in recent years, appropriate drug therapy selection has increased, and drug treatment regimens can be registered and managed in each facility. CINV can be representative of a patient's pain even when the mechanisms of Emesis have been elucidated and drugs acting on it have been developed.

The JSCO had published their first clinical practice guideline for antiemesis in 2010, which had attracted considerable attention from medical professionals in Japan, including physicians, nurses and pharmacists. As previously described [8], the JSCO conducted an interview searching for the penetration of the antiemetic guideline among organizations participating in the 2012 JSCO annual meeting. In this survey, 586 (51.0\%) Japanese medical staff provided antiemetic therapies according to the guideline, while 489 (42.6\%) actually referred to it. After determining the discrepancy between guideline recommendations and medical practice, the study identified institutional clinical situation, domestic insurance application, and patient and doctor preferences as reasons for such a discrepancy [78].

To improve the quality of the antiemetic guideline, the JSCO organized a guideline evaluation team that functioned independently from the guideline update committee. A second version had been published based on the need for (1) creating guidelines considering the needs and current situation in Japan and (2) actively obtaining high-level evidence test results in Japan (https://www.jsco-cpg.jp/item/29/ index.html). In addition, the Japanese antiemetic guideline has been updated every 2-3 years with the availability of new evidence, such as the addition olanzapine to standard therapy and steroid-sparing therapy. Carboplatin has been categorized as a moderately emetogenic agent by this second version guideline. However, the JSCO antiemetic guideline update committee recategorized carboplatin as a highly emetogenic chemotherapeutic agent according to clinical handling in Japan and guidelines with a high-level consensus. As such, the description for the categorization of carboplatin in the JSCO antiemetic guideline website and subsequent revised versions should be changed.

While the second version of the guideline had not been constructed based on the international guideline construction method introduced by Medical Information Network Distribution Service (Minds) 2014, the JSCO antiemetic guideline update committee will be following this methodology for the next version. For effective antiemetic care of Japanese patients with cancer, continuous improvement in the quality of the antiemetic guideline is imperative.

We herein presented an updated summary of the second version of the JSCO antiemetic guideline, which showed high concordance with other international antiemetic guidelines based on high-level evidence. Overall, proper application of antiemetic therapy may lead to excellent anticancer therapy outcome among Japanese patients with cancer.

Acknowledgements Special thanks to the guideline evaluation members Prof. Mitsue Saito (Department of Breast and Endocrine Surgery, Juntendo University, Tokyo), Prof. Yusuke Tanigawara (Department of Pharmacokinetics and Pharmacodynamics, Keio University, Tokyo), and RN. Yukino Ashikaga (Kobe Education Center, Japanese Nursing Association) for providing recommendations in evidence selection and precise descriptions that improved the quality of the guideline. The authors thank Misao Oda for constant support throughout the revision procedure, Hitomi Sasaki for excellent contributions to the publication of the revised version, and Kyoko Hamada for considerable contributions to the publication of this English version. The authors also would like to thank Enago (https://www.enago.jp) for the English language review.

\section{Compliance with ethical standards}

Conflict of interest Aogi Kenjiro received lecture fees from Taiho Pharmaceutical Co., Ltd./Ono Pharmaceutical Co., Ltd. and research funding from Chugai Pharmaceutical Co., Ltd. Saeki Toshiaki received 
lecture fees from Ono Pharmaceutical Co., Ltd./Taiho Pharmaceutical Co., Ltd. Tamura Kazuo received lecture fees from SymBio Pharmaceuticals Limited./AC Medical Co., Ltd. Nakagawa Kazuhiko received lecture fees from AstraZeneca K.K./Astellas Pharma Inc./MSD K.K./ Ono Pharmaceutical Co., Ltd./Nippon Boehringer Ingelheim Co., Ltd./ Novartis Pharma K.K./Pfizer Japan Inc./Clinical Trial Co., Ltd./Medicus Shuppan, Publishers Co., Ltd./Care Net, Inc./Reno. Medical K.K./ Kyorin Pharmaceutical Co., Ltd./Medical Review Co., Ltd./Roche Diagnostics K.K./Bayer Yakuhin, Ltd./Medical Mobile Communications Co., Ltd./3H Clinical Trial Inc./Nichi-Iko Pharmaceutical Co., Ltd./ Takeda Pharmaceutical Co., Ltd./Taiho Pharmaceutical Co., Ltd./Bristol Myers Squibb Company/Eli Lilly Japan K.K./SymBio Pharmaceuticals Limited./Chugai Pharmaceutical Co., Ltd./Nanzando Co., Ltd./ Yodosha Co., LTD./Nikkei Business Publications, Inc./Daiichi Sankyo Co., Ltd./Thermo Fisher Scientific K.K./Yomiuri Telecasting Corporation/Nippon Kayaku Co., Ltd./Merck Biopharma Co., Ltd./AbbVie Inc. and research funding from MSD K.K./A2 Healthcare Corp./inVentiv Health Japan/Astellas Pharma Inc./Daiichi Sankyo Co., Ltd./ Novartis Pharma K.K./AbbVie Inc./Quintiles Inc./IQVIA Services Japan K.K./ICON Japan K.K./Chugai Pharmaceutical Co., Ltd./Takeda Pharmaceutical Co., Ltd./EP-CRSU Co., Ltd./Oncology Inc./Linical Co., Ltd./Eli Lilly Japan K.K./Co., Ltd./Bristol Myers Squibb Company/Nippon Boehringer Ingelheim Co., Ltd./Taiho Pharmaceutical Co., Ltd./Japan Inc./International Corp./SymBio Pharmaceuticals Limited/Ono Pharmaceutical Co., Ltd./Merck Serono Co., Ltd./Merck Biopharma Co., Ltd./AstraZeneca K.K./CMIC Shift Zero K.K./Pharmaceutical Co., Ltd./Kyowa Hakko Kirin Co., Ltd./EPS Corporation./ Bayer Yakuhin, Ltd./Syneos Health./EPS International Co., Ltd./Pfizer R\&D Japan G.K./Otsuka Pharmaceutical Co., Ltd. and consulting or advisory fees from Takeda Pharmaceutical Co., Ltd./Kyorin Pharmaceutical Co., Ltd./Ono Pharmaceutical Co., Ltd./Pfizer Japan Inc./ Eli Lilly Japan K.K. Boku Narikazu received lecture fees from Taiho Pharmaceutical Co., Ltd./Ono Pharmaceutical Co., Ltd./Bristol-Myers Squibb Company and research funding from Ono Pharmaceutical Co., Ltd./Taiho Pharmaceutical Co., Ltd./Takeda Pharmaceutical Co., Ltd. Iihara Hirotoshi received research funding from Ono Pharmaceutical Co., Ltd. Ohtani Shoichiro received lecture fees from Chugai Pharmaceutical Co., Ltd./Eisai Co., Ltd./Eli Lilly Japan K.K./Pfizer Japan Inc./AstraZeneca K.K. Takeda Masayuki received lecture fees from Nippon Boehringer Ingelheim Co., Ltd./Chugai Pharmaceutical Co., Ltd./AstraZeneca K.K./Ono Pharmaceutical Co., Ltd./Novartis Pharma K.K. The rest of the authors have no conflicts of interest.

Open Access This article is licensed under a Creative Commons Attribution 4.0 International License, which permits use, sharing, adaptation, distribution and reproduction in any medium or format, as long as you give appropriate credit to the original author(s) and the source, provide a link to the Creative Commons licence, and indicate if changes were made. The images or other third party material in this article are included in the article's Creative Commons licence, unless indicated otherwise in a credit line to the material. If material is not included in the article's Creative Commons licence and your intended use is not permitted by statutory regulation or exceeds the permitted use, you will need to obtain permission directly from the copyright holder. To view a copy of this licence, visit http://creativecommons.org/licenses/by/4.0/.

\section{References}

1. Jordan K, Jahn F, Aapro M (2015) Recent developments in the prevention of chemotherapy-induced nausea and vomiting (CINV): a comprehensive review. Ann Oncol 26:1081-1090
2. Naeim A, Dy SM, Lorenz KA et al (2008) Evidence-based recommendations for cancer nausea and vomiting. J Clin Oncol 26:3903-3910

3. Hesketh PJ (2008) Chemotherapy-induced nausea and vomiting. N Engl J Med 358:2482-2494

4. NCCN Clinical Practice Guidelines in Oncology-Antiemesis-ver. 1,2015

5. MASCC/ESMO-Antiemetic Guidelines 2013

6. Antiemetics (2011) American Society of Clinical Oncology clinical practice guideline update. J Clin Oncol 29:4189-4198

7. Takeuchi H, Saeki T, Aiba K et al (2016) Japanese Society of Clinical Oncology clinical practice guidelines 2010 for antiemesis in oncology: executive summary. Int J Clin Oncol 21:1-12

8. Saeki T, Tamura K, Aiba K et al (2015) The survey for anti-emetic guideline by using questioner. Gan To Kagaku Ryoho 42:305-311

9. https://www.jsco-cpg.jp/item/29/index.html(in Japanese)

10. The Cochrane library. https://www.cochranelibrary.com/

11. Nagashima K, Iwasa S, Yanai T et al (2015) A double-blind randomized phase II study of olanzapine $10 \mathrm{mg}$ versus $5 \mathrm{mg}$ for emesis induced by highly emetogenic chemotherapy. Jpn J Clin Oncol 45:229-231

12. Navari RM, Nagy CK, Gray SE (2013) The use of olanzapine versus metoclopramide for the treatment of breakthrough chemotherapy-induced nausea and vomiting in patients receiving highly emetogenic chemotherapy. Support Care Cancer 21:1655-1663

13. Navari RM, Einhorn LH, Passik SD et al (2005) A phase II trial of olanzapine for the prevention of chemotherapy-induced nausea and vomiting: a Hoosier Oncology Group study. Support Care Cancer 13:529-534

14. Navari RM, Einhorn LH, Loehrer PJ Sr et al (2007) A phase II trial of olanzapine, dexamethasone, and palonosetron for the prevention of chemotherapy-induced nausea and vomiting: a Hoosier oncology group study. Support Care Cancer 15:1285-1291

15. Tan L, Liu J, Liu X et al (2009) Clinical research of Olanzapine for prevention of chemotherapy-induced nausea and vomiting. $\mathrm{J}$ Exp Clin Cancer Res 28:131-138

16. Navari RM, Gray SE, Kerr AC (2011) Olanzapine versus aprepitant for the prevention of chemotherapy-induced nausea and vomiting: a randomized phase III trial. J Support Oncol 9:188-195

17. Aapro M, Fabi A, Nolè F et al (2010) Double-blind, randomised, controlled study of the efficacy and tolerability of palonosetron plus dexamethasone for 1 day with or without dexamethasone on days 2 and 3 in the prevention of nausea and vomiting induced by moderately emetogenic chemotherapy. Ann Oncol 21:1083-1088

18. Celio L, Frustaci S, Denaro A et al (2011) Palonosetron in combination with 1-day versus 3-day dexamethasone for prevention of nausea and vomiting following moderately emetogenic chemotherapy: a randomized, multicenter, phase III trial. Support Care Cancer 19:1217-1225

19. Roscoe JA, Heckler CE, Morrow GR et al (2012) Prevention of delayed nausea: a University of Rochester Cancer Center Community Clinical Oncology Program study of patients receiving chemotherapy. J Clin Oncol 30:3389-3395

20. Komatsu Y, Okita K, Yuki S et al (2015) Open-label, randomized, comparative, phase III study on effects of reducing steroid use in combination with Palonosetron. Cancer Sci 106:891-895

21. Ettinger DS, Eisenberg PD, Fitts D et al (1996) A double-blind comparison of the efficacy of two dose regimens of oral granisetron in preventing acute emesis in patients receiving moderately emetogenic chemotherapy. Cancer 78:144-1451

22. Chawla SP, Grunberg SM, Gralla RJ et al (2003) Establishing the dose of the oral NK1 antagonist aprepitant for the prevention of chemotherapy induced nausea and vomiting. Cancer 97:2290-2300 
23. Hesketh PJ, Grunberg SM, Gralla RJ et al (2003a) The oral neurokinin-1 antagonist aprepitant for the prevention of chemotherapy-induced nausea and vomiting: a multinational, randomized, double-blind, placebo-controlled trial in patients receiving highdose cisplatin-the Aprepitant Protocol 052 Study Group. J Clin Oncol 21:4112-4119

24. de Wit R, Herrstedt J, Rapoport B et al (2004) The oral NK1 antagonist, aprepitant, given with standard antiemetics provides protection against nausea and vomiting over multiple cycles of cisplatin-based chemotherapy: a combined analysis of two randomized, placebocontrolled phase III clinical trials. Eur J Cancer 40:403-410

25. Grunberg S, Chua D, Maru A et al (2011) Single-dose fosaprepitant for the prevention of chemotherapy-induced nausea and vomiting associated with cisplatin therapy: randomized, doubleblind study protocol-EASE. J Clin Oncol 29:1495-1501

26. Aapro MS, Grunberg SM, Manikhas GM et al (2006) A phase III, double-blind, randomized trial of palonosetron compared with ondansetron in preventing chemotherapy-induced nausea and vomiting following highly emetogenic chemotherapy. Ann Oncol 17:1441-1449

27. Saito M, Aogi K, Sekine I et al (2009) Palonosetron plus dexamethasone versus granisetron plus dexamethasone for prevention of nausea and vomiting during chemotherapy: a double-blind, double-dummy, randomised, comparative phase III trial. Lancet Oncol 10:115-124

28. Nishimura J, Satoh T, Fukunaga M et al (2015) Combination antiemetic therapy with aprepitant/fosaprepitant in patients with colorectal cancer receiving oxaliplatin-based chemotherapy (SENRI trial): a multicentre, randomised, controlled phase 3 trial. Eur J Cancer 51:1274-1282

29. Hesketh PJ, Grunberg SM, Gralla RJ et al (2003b) The oral neurokinin-1 antagonist aprepitant for the prevention of chemotherapy-induced nausea and vomiting: a multinational, randomized, double-blind, placebo-controlled trial in patients receiving highdose cisplatin-the Aprepitant Protocol 052 Study Group. J Clin Oncol 21:4112-4119

30. Poli-Bigelli S, Rodrigues-Pereira J, Carides AD et al (2003a) Addition of the neurokinin 1 receptor antagonist aprepitant to standard antiemetic therapy improves control of chemotherapy-induced nausea and vomiting: results from a randomized, double-blind, placebo controlled trial in Latin America. Cancer 97:3090-3098

31. Warr DG, Hesketh PJ, Gralla RJ et al (2005) Efficacy and tolerability of aprepitant for the prevention of chemotherapy-induced nausea and vomiting in the patients with breast cancer after moderately emetogenic chemotherapy. J Clin Oncol 23:2822-2830

32. Kris MG, Radford JE, Pizzo BA et al (1997) Use of a NK1 receptor antagonist to prevent delayed emesis after cisplatin. J Natl Cancer Inst 89:817-818

33. Schmoll HJ, Aapro MS, Poli-Bigelli S et al (2006) Comparison of an aprepitant regimen with a multiple-day ondansetron regimen, both with dexamethasone, for antiemetic efficacy in high-dose cisplatin treatment. Ann Oncol 17:1000-1006

34. Hashimoto H, Yamanaka T, Shimada Y et al (2013) Palonosetron (PALO) versus granisetron (GRA) in the triplet regimen with dexamethasone (DEX) and aprepitant (APR) for preventing chemotherapy-induced nausea and vomiting (CINV) in patients (pts) receiving highly emetogenic chemotherapy (HEC) with cisplatin (CDDP): A randomized, double-blind, phase III trial. J Clin Oncol 31(supple; abstr 9621)

35. Hashimoto $\mathrm{H}$, Abe M, Tokuyama O et al (2020) Olanzapine $5 \mathrm{mg}$ plus standard antiemetic therapy for the prevention of chemotherapy-induced nausea and vomiting (J-FORCE): a multicentre, randomised, double-blind, placebo-controlled, phase 3 trial. Lancet Oncol 21:242-249
36. Matsumoto K, Takahashi M, Sato K et al (2015) Palonosetron or granisetron for prevention of CINV in patients with breast cancer receiving dexamethasone and fosaprepitant following anthracycline plus cyclophosphamide (AC) regimen. J Clin Oncol 33(supple; abstr 9598)

37. Matsumoto K, Takahashi M, Sato K et al (2020) A double-blind, randomized, multicenter phase 3 study of palonosetron vs granisetron combined with dexamethasone and fosaprepitant to prevent chemotherapy-induced nausea and vomiting in patients with breast cancer receiving anthracycline and cyclophosphamide. Cancer Med. (Epub ahead of print)

38. The Italian Group for Antiemetic Research (2000) Dexamethasone alone or in combination with ondansetron for the prevention of delayed nausea and vomiting induced by chemotherapy. N Engl J Med 342:1554-1559

39. Koo WH, Ang PT (1996) Role of maintenance oral dexamethasone in prophylaxis of delayed emesis caused by moderately emetogenic chemotherapy. Ann Oncol 7:71-74

40. Geling O, Eichler HG (2005) Should 5-hydroxytryptamine-3 receptor antagonists be administered beyond 24 hours after chemotherapy to prevent delayed emesis? Systematic re-evaluation of clinical evidence and drug cost implications. J Clin Oncol 23:1289-1294

41. Eisenberg P, Figueroa-Vadillo J, Zamora R et al (2003) Improved prevention of moderately emetogenic chemotherapy-induced nausea and vomiting with palonosetron, a pharmacologically novel 5-HT3 receptor antagonist: results of a phase III, single-dose trial versus dolasetron. Cancer 98:2473-2482

42. Lindley C, Goodin S, McCune J et al (2005) Prevention of delayed chemotherapy-induced nausea and vomiting after moderately high to highly emetogenic chemotherapy: comparison of ondansetron, prochlorperazine, and dexamethasone. Am J Clin Oncol 28:270-276

43. Rapoport BL, Jordan K, Boice JA et al (2010) Aprepitant for the prevention of chemotherapy-induced nausea and vomiting associated with a broad range of moderately emetogenic chemotherapies and tumor types: a randomized, double-blind study. Support Care Cancer 18:423-431

44. Aapro MS, Alberts DS (1981) High-dose dexamethasone for prevention of cisplatin-induced vomiting. Cancer Chemother Pharmacol 7:11-14

45. Ioannidis JP, Hesketh PJ, Lau J (2000) Contribution of dexamethasone to control chemotherapy-induced nausea and vomiting; a meta-analysis of randomized evidence. J Clin Oncol 18:3409-3422

46. Grunberg SM (2007) Antiemetic activity of corticosteroids in patients receiving cancer chemotherapy: dosing, efficacy, and tolerability analysis. Ann Oncol 18:233-240

47. Sekine S, Nishiwaki Y, Kakinuma R et al (1997) Phase II study of high-dose dexamethasone-based association in acute and delayed high-dose cisplatin-induced emesis JCOG study 9413. Br J Cancer 76:90-92

48. Glare P, Pereira G, Kristjanson LJ et al (2004) Systematic review of the efficacy of antiemetics in the treatment of nausea in patients with far-advanced cancer. Support Care Cancer $12: 432-440$

49. Jones JM, Qin R, Bardia A et al (2011) Antiemetics for chemotherapy-induced nausea and vomiting occurring despite prophylactic antiemetic therapy. J Palliat Med 14:810-814

50. Ettinger DS, Bierman PJ, Bradbury B et al (2007) National comprehensive Cancer Network (NCCN). J Natl Compr Cancer Netw 5:12-33

51. Valle JW, Wasan HS, Palmer DH et al (2010) Cisplatin plus gemcitabine versus gemcitabine for biliary tract cancer. N Engl J Med 362:1273-1281 
52. Williams SD, Birch R, Einhorn LH et al (1987) Treatment of disseminated germ-cell tumors with cisplatin, bleomycin, and either vinblastine or etoposide. N Engl J Med 316:1435-1440

53. Morrow GR, Morrel C (1982) Behavioral treatment for the anticipatory nausea and vomiting induced by cancer chemotherapy. $\mathrm{N}$ Engl J Med 307:1476-1480

54. Morrow GR, Lindke J, Black PM et al (1991) Predicting development of anticipatory nausea in cancer patients: prospective examination of right clinical characteristics. J Pain Sympt Manag $6: 215-223$

55. Andrykowski MA, Jacobsen PB, Marks E et al (1988) Prevalence, predictors, and course of anticipatory nausea in women receiving adjuvant chemotherapy for breast cancer. Cancer 62:2607-2613

56. Alba E, Bastus R, de Andres L et al (1989) Anticipatory nausea and vomiting: prevalence and predictors in chemotherapy patients. Oncology 46:26-30

57. Morrow GR (1982) Prevalence and correlates of anticipatory nausea and vomiting in chemotherapy patients. J Natl Cancer Inst 68:585-588

58. Feyer PC, Stewart AL, Titlbach OJ et al (1998) Aetiology and prevention of emesis induced by radiotherapy. Support Care Cancer 6:253-260

59. Spitzer TR, Friedman CJ, Bushnell W et al (2000) Double-blind, randomized, parallel-group study on the efficacy and safety of oral granisetron and oral ondansetron in the prophylaxis of nausea and vomiting in patients receiving hyperfractionated total body irradiation. Bone Marrow Transplant 26:203-210

60. Tonato M, Rolia F, Del Favero A et al (1991) Methodology of antiemetic trials. Ann Oncol 2:107-114

61. Rolia F, Tonato M, Basurto C et al (1987) Antiemetic activity of high doses of metoclopramide combined with methylprednisolone versus metoclopramide alone in cisplatin-treated cancer patients: a randomized double-blind trial of the Italian Oncology Group for Clinical Research. J Clin Oncol 5:141-149

62. Sullivan JR, Leyden MJ, Bell R et al (1983) Decreased cisplatininduced nausea and vomiting with chronic alcohol ingestion. $\mathrm{N}$ Engl J Med 309:796

63. Tamura K, Aiba K, Saeki T et al (2015) Testing the effectiveness of antiemetic guidelines: results of a prospective registry by the CINV Study Group of Japan. Int J Clin Oncol 20:855-865

64. Hawker GA, Mian S, Kendzerska T et al (2011) Measures of adult pain: Visual Analog Scale for Pain (VAS Pain), Numeric Rating Scale for Pain (NRS Pain), McGill Pain Questionnaire (MPQ), Short-Form McGill Pain Questionnaire (SF-MPQ), Chronic Pain Grade Scale (CPGS), Short Form-36 Bodily Pain Scale (SF-36 BPS), and Measure of Intermittent and Constant Osteoarthritis Pain (ICOAP). Arthritis Care Res (Hoboken) 63(Suppl 11):S240-S252

65. Rhodes VA, McDaniel RW (1999) The Index of Nausea, Vomiting, and Retching: a new format of the index of Nausea and Vomiting. Oncol Nurs Forum 26:889-894

66. MASCC antiemesis tool (MAT) https://www.mascc.org/mat
67. Morrow GR (1992) A patient report measure for the quantification of chemotherapy induced nausea and emesis: psychometric properties of the Morrow assessment of nausea and emesis (MANE). Br J Cancer 66:72-74

68. Lindley CM, Hirsch JD, O'Neill CV et al (1992) Quality of life consequences of chemotherapy-induced emesis. Qual Life Res 66:72-74

69. Ihbe-Heffinger A, Ehlken B, Bernard R et al (2004) The impact of delayed chemotherapy-induced nausea and vomiting on patients, health resource utilization and costs in German cancer centers. Ann Oncol 15:526-536

70. Miller PJ, Balu S, Buchner D et al (2013) Willingness to pay to prevent chemotherapy induced nausea and vomiting among patients with breast, lung, or colorectal cancer. J Med Econ 16:1179-1189

71. Hasler SB, Hirt A, Luethy AR et al (2008) Safety of ondansetron loading doses in children with cancer. Support Care Cancer 16:469-475

72. Sepulveda-Vildosola AC, Betanzos-Cabrera Y, Lastiri GG et al (2008) Palonosetron hydrochloride is an effective and safe option to prevent chemotherapy-induced nausea and vomiting in children. Arch Med Res 39:601-606

73. Gore L, Chawla S, Petrilli A et al (2009) Aprepitant in adolescent patients for prevention of chemotherapy-induced nausea and vomiting: a randomized double-blind, placebo-controlled study of efficacy and tolerability. Pediatr Blood Cancer 52:242-247

74. Talley NJ, Meineche-Schmidt V, Pare P et al (1998) Efficacy of omeprazole in functional dyspepsia: double-blind, randomized, placebo-controlled trials. Aliment Pharmacol Ther 12:1055-1065

75. del Giglio A, Soares HP, Caparroz C et al (2000) Granisetron is equivalent to ondansetron for prophylaxis of chemotherapyinduced nausea and vomiting: results of a meta-analysis of randomized controlled trials. Cancer 89:2301-2308

76. McCrea JB, Majumdar AK, Goldberg MR et al (2003) Effects of the neurokinin1 receptor antagonist aprepitant on the pharmacokinetics of dexamethasone and methylprednisolone. Clin Pharmacol Ther 74:17-24

77. Depre M, Van Hecken A, Oeyen M et al (2005) Effect of aprepitant on the pharmacokinetics and pharmacodynamics of warfarin. Eur J Clin Pharmacol 61:341-346

78. Poli-Bigelli S, Rodrigues-Pereira J, Carides AD et al (2003b) Addition of the neurokinin-1 receptor antagonist aprepitant to standard antiemetic therapy improves control of chemotherapy induced nausea and vomiting: results from a randomized, double-blind, placebo-controlled trial in Latin America. Cancer 97:3030-3038

Publisher's Note Springer Nature remains neutral with regard to jurisdictional claims in published maps and institutional affiliations.

\section{Affiliations}

Kenjiro Aogi ${ }^{1} \cdot$ Hideki Takeuchi ${ }^{2,3,4} \cdot$ Toshiaki Saeki $^{4}\left(\right.$ D $\cdot$ Keisuke Aiba $^{5,6} \cdot$ Kazuo Tamura $^{7} \cdot$ Keiko lino $^{8}$. Chiyo K. Imamura ${ }^{9,10} \cdot$ Kenji Okita $^{11,12}$ - Yoshikazu Kagami ${ }^{13} \cdot$ Ryuhei Tanaka $^{14} \cdot$ Kazuhiko Nakagawa $^{15}$. Hirofumi Fujii ${ }^{16}$. Narikazu Boku ${ }^{17}$. Makoto Wada ${ }^{18}$. Tatsuo Akechi ${ }^{19}$. Hirotoshi lihara ${ }^{20}$. Shoichiro Ohtani ${ }^{21}$. Ayako Okuyama ${ }^{22} \cdot K_{e i k o} \mathrm{Ozawa}^{23} \cdot$ Yong-II Kim $^{24,25} \cdot$ Hidenori Sasaki $^{26} \cdot$ Yasuo Shima $^{27} \cdot$ Masayuki Takeda $^{15}$. Eijiro Nagasaki $^{5,6} \cdot$ Toshihiko Nishidate $^{11,12} \cdot$ Takahiro Higashi $^{22} \cdot$ Kouichi Hirata $^{11,12}$ 
1 Department of Breast Oncology, National Hospital Organization Shikoku Cancer Center, Ehime, Japan

2 Department of Breast Oncology, Saitama Medical University, Saitama, Japan

3 Department of Breast Surgical Oncology, Japan Organization of Occupational Health and Safety Yokohama Rosai Hospital, Yokohama, Japan

4 Department of Breast Oncology, Saitama Medical University International Medical Center, Saitama, Japan

5 Division of Clinical Oncology/Hematology, Department of Internal Medicine, Jikei University School of Medicine, Tokyo, Japan

6 Todachuo General Hospital, Saitama, Japan

7 General Medical Research Center, Fukuoka University Hospital, Fukuoka, Japan

8 Department of Adult Nursing, National College of Nursing, Tokyo, Japan

9 Department of Clinical Pharmacokinetics and Pharmacodynamics, Keio University, Tokyo, Japan

10 Advanced Cancer Translational Research Institute, Showa University, Tokyo, Japan

11 Department of Surgery, Surgical Oncology and Science, Sapporo Medical University Postgraduate School of Medicine, Sapporo, Hokkaido, Japan

12 JR Sapporo Hospital, Sapporo, Hokkaido, Japan

13 Division of Radiation Oncology, Department of Radiology, Showa University School of Medicine, Tokyo, Japan

14 Department of Pediatric Hematology and Oncology, Saitama Medical University International Medical Center, Saitama, Japan
15 Department of Medical Oncology, Faculty of Medicine, Kindai University, Osaka, Japan

16 Department of Clinical Oncology, Jichi Medical University, Tochigi, Japan

17 Gastrointestinal Medical Oncology Division, National Cancer Center Hospital, Tokyo, Japan

18 Department of Psycho-Oncology and Palliative Medicine, Osaka International Cancer Institute, Osaka, Japan

19 Department of Psychiatry and Cognitive-Behavioral Medicine, Nagoya City University Graduate School of Medical Sciences, Aichi, Japan

20 Department of Pharmacy, Gifu University Hospital, Gifu, Japan

21 Department of Breast Surgery, Hiroshima City Hiroshima Citizens Hospital, Hiroshima, Japan

22 Center for Cancer Control and Information Services, National Cancer Center, Tokyo, Japan

23 Department of Nursing, NTT Medical Center Tokyo, Tokyo, Japan

24 Department of Medical Oncology, Seirei Hamamatsu General Hospital, Sizuoka, Japan

25 Department of Medical Oncology, Yodogawa Christian Hospital, Osaka, Japan

26 Division of Medical Oncology, Hematology and Infectious Disease, Department of Medicine, Fukuoka University Hospital, Fukuoka, Japan

27 Department of Palliative Medicine, Tsukuba Medical Center Hospital, Ibaraki, Japan 